\title{
A Review on the Application of Friction Models in Wheel-Rail Adhesion Calculation
}

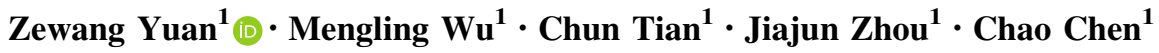

Received: 5 January 2021/Revised: 30 January 2021/Accepted: 5 February 2021/Published online: 8 March 2021

(C) The Author(s) 2021

\begin{abstract}
Friction is the bond linking the tangential and normal forces at the wheel-rail interface. Modeling friction is the precondition for the wheel-rail adhesion calculation. In this work, the critical role of friction in the calculation of wheel-rail adhesion is discussed. Four types of friction models (Coulomb model, linear model + Coulomb model, rational model and exponential model) which are commonly used for the calculation of wheel-rail adhesion are reviewed, in particular with regard to their structural characteristics and application state. The adhesion coefficients calculated from these four friction models using the Polach model are analyzed by comparison with the measured values. The rational model and the exponential model are more flexible for defining the falling friction, and the adhesion coefficient calculated by these two models is highly consistent with the measured one. Though the rational model and exponential model describe the falling friction well, the existing friction models are not applicable for calculating adhesion after considering more realistic factors, such as thermal effect, contaminants and so on. Developing a novel and practical friction model to accurately describe the wheel-rail friction behavior is still an essential but challenging and significant task. This review provides a reference for the selection of existing friction models and generates fresh insights into developing novel and practical friction models.
\end{abstract}

Zewang Yuan

0746yzw@tongji.edu.cn

1 Institute of Rail Transit, Tongji University, Shanghai, China

Communicated by Gary Barber.
Keywords Wheel-rail contact · Friction model · Adhesion calculation $\cdot$ Adhesion coefficient $\cdot$ Sliding speed

\section{Introduction}

The tangential forces arising from the relative motion between wheel and rail are described as adhesion forces, which accelerate, brake, and guide the vehicle $[1,2]$. These forces act in extremely small (around $1 \mathrm{~cm}^{2}$ ) wheel-rail contact areas, yet have a dramatic influence on wheel-rail contact mechanics and vehicle dynamics. Friction is the bond linking the tangential and normal forces at the wheelrail interface [3, 4]. Modeling friction is a precondition for the wheel-rail adhesion calculation.

During the past few decades, several friction models have been developed and applied to wheel-rail adhesion calculations. The Coulomb model is the first and the most long-lived friction model used in wheel-rail adhesion calculation, dating back to Carter and Fromm's two-dimensional contact theory in the 1920s [5, 6]. However, the history of the Coulomb model goes back centuries to Amontons' and Coulomb's work. In 1699, the French physicist Amontons [7] established a friction law experimentally. In the eighteenth century, after further research based on Amontons' work, Coulomb [8] proposed a friction law. The main characteristic of Coulomb's law is that the friction coefficient is constant, and does not change by varying factors such as speed, contact pressure and so on. With further research, a significant difference was found between the actual friction behavior and that described by Coulomb's law. Several velocity-dependent friction models were subsequently developed to accurately describe the falling friction and to calculate the adhesion. Bochet [9] proposed an empirical equation with a rational function for 
the friction coefficient by using the test data from wheelrail sliding experiments on the Lyon line. This rational model has since been widely used for the calculation of wheel-rail adhesion. Kragelski et al. [10] proposed a velocity-dependent friction model with exponential function which has excellent flexibility for defining the friction coefficient. Giménez et al. [11] established a linear relationship between the friction coefficient and the local sliding speed, which was integrated into the FASTSIM algorithm. Giménez's model overcomes the limitation caused by using a constant friction coefficient and presents the falling friction approximately in a small speed range. Extensive research has been conducted on the modeling and application of friction. However, up to now, far too little attention has been paid to the review work on the friction model applied in the adhesion calculation. Comparative studies on different friction models carried out by Rovira et al. [12], Vollebregt et al. [13] and Meymand et al. [14] are far from satisfying this need.

The main aim of this paper is to combine and classify multiple sources and give a comprehensive overview of the existing friction models applied to the calculation of wheelrail adhesion. Assuming a train traveling in a straight line, the effect of two-point contacts in testing is not considered in this review work. In the remainder of the paper, the critical role of friction in the calculation of wheel-rail adhesion is discussed. Four types of friction models (Coulomb model, linear model + Coulomb model, rational model and exponential model) which are commonly used for the calculation of wheel-rail adhesion are reviewed, in particular with regard to their structural characteristics and application state; using Polach's model, the adhesion coefficients calculated from these four friction models are compared with the measurements. The challenges involved in developing better friction models to describe the wheelrail friction behavior when considering more realistic factors such as the thermal effect and contaminants are also discussed. This review provides a reference for the selection of existing friction models and generates fresh insights into developing novel and practical friction models.

\section{The Critical Role of Friction}

Both theoretical and experimental studies have shown that there is not only an adhesion area with pure rolling motion in the contact area, but also a sliding area with a nonzero relative speed $[3,5,15]$, as shown in Fig. 1. The rolling direction of the wheel is from left to right under braking conditions, and $p_{s \tau}$ is the maximum possible normalized tangential stress. The actual tangential stress $p_{\tau}$ in the contact area can be obtained from subtracting a semicircle $p_{a \tau}$ from $p_{s \tau}$ in the adhesion area [5].

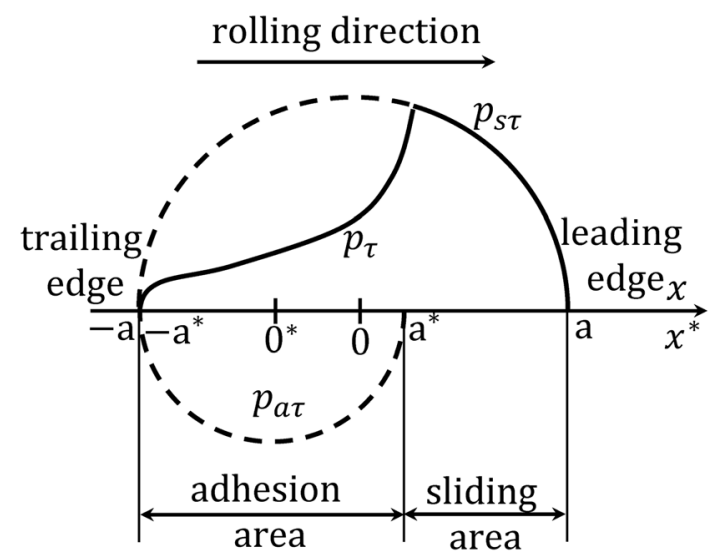

Fig. 1 Adhesion area and sliding area in the contact area [16]

Previous studies assumed that the tangential stress $p_{\tau}$ and the normal stress $p_{z}$ satisfied the local Coulomb friction law [17-22], as shown in Eq. (1). In the adhesion area of the contact area, the tangential stress $p_{\tau}$ is not greater than the product of the friction coefficient $f$ and the normal stress $p_{z}$. In the sliding area, the tangential stress $p_{\tau}$ is equal to the product of the friction coefficient $f$ and the normal stress $p_{z}[17,19-21]$. The total tangential forces exchanged between wheel and rail are calculated by integrating the tangential stress on the entire contact area. From Eq. (1), it can be seen that the friction coefficient directly determines the calculated results of the wheel-rail adhesion.

$$
\begin{aligned}
& \left|p_{\tau}\right| \leq f \cdot p_{z},\left|v_{\tau}\right|=0 \\
& \left|p_{\tau}\right|=-f \cdot p_{z} \cdot \frac{v_{\tau}}{\left|v_{\tau}\right|},\left|v_{\tau}\right| \neq 0
\end{aligned}
$$

where $p_{\tau}$ and $p_{z}$ are the tangential stress and normal stress, respectively, $v_{\tau}$ is the relative sliding speed in tangential between the wheel and rail, and $f$ is the friction coefficient.

\section{Friction Models}

\subsection{The Coulomb Model}

The expression of the Coulomb model can be written as follows:

$f=\operatorname{csgn}(v)$,

where $f$ is the friction coefficient, $c$ is a constant, $\operatorname{sgn}()$ is the sign function, and $v$ is the sliding speed.

In the Coulomb model, the friction coefficient is a constant. That is to say, there is no distinction between the static and kinetic friction coefficients. With such a simple structure, the Coulomb model has greatly facilitated the process of wheel-rail adhesion calculation. Therefore, the Coulomb model was widely used in early wheel-rail contact theories for calculating adhesion forces, including 
Carter's [5] and Fromm's [6] two-dimensional rolling contact theory, Vermeulen and Johnson's [23] three-dimensional rolling contact theory, and Shen et al.'s [24] and Kalker's [18, 25] previous studies. With the application of the finite element method (FEM) to the analysis of the wheel-rail contact problems, the Coulomb model is also commonly used to define the relationship between the wheel and rail [26-33]. The main reason for its preference is not accuracy, but simplicity.

After reaching its saturation value, the wheel-rail adhesion coefficient calculated by adopting the Coulomb model remains constant [1]. However, in actuality, it is found that the adhesion coefficient varies with the sliding speed [34-43]. Figure 2 shows the large difference between the calculated and measured adhesion coefficients.

The adhesion-creepage curve was measured by the authors on a full-scale wheel-rail roller rig at a speed of 200 $\mathrm{km} / \mathrm{h}$ with an axle load of $13 \mathrm{t}$ under wet conditions. The schematic of the full-scale wheel-rail roller rig is shown in Fig. 3, and the major parameters of the roller rig are listed in Table 1 . The axle load was simulated by the weights on the simulated vehicle body. The inertia of the bogie was simulated by the flywheels connected to the rollers, which were driven by the motors. When the vehicle speed reached a preset value, braking force was applied on the wheel to produce a slip between the wheel and roller. It can be seen from the Fig. 2 that the measured adhesion-creepage curve decreases after reaching the peak value, while the calculated adhesion-creepage curve remains constant after reaching its saturation value. The reason for this difference is that the friction coefficient from the Coulomb model is constant and is unrelated to the sliding speed. Therefore, the Coulomb model with a constant friction coefficient is unreliable in the application of adhesion calculation.

However, as the research moved along, it was found that the friction coefficient is not constant, but a velocity-

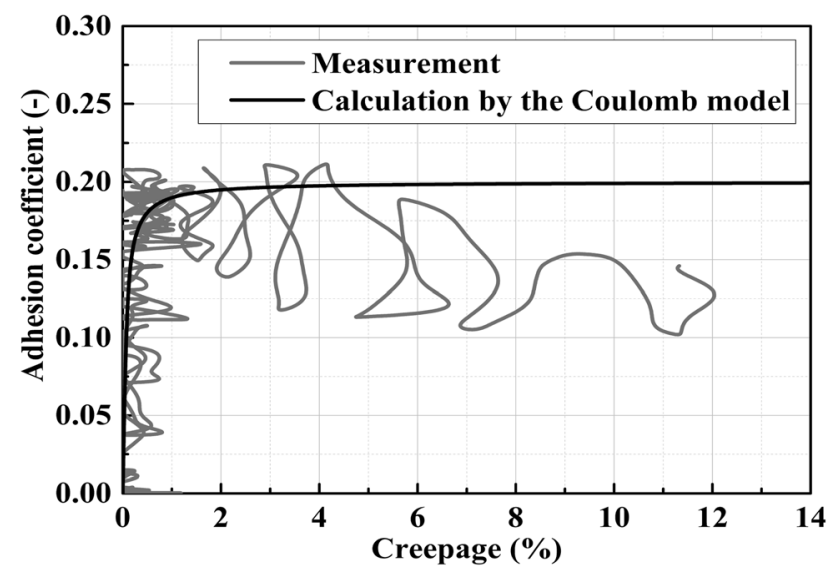

Fig. 2 Adhesion coefficient calculated by adopting the Coulomb model and tested by full-scale roller rig
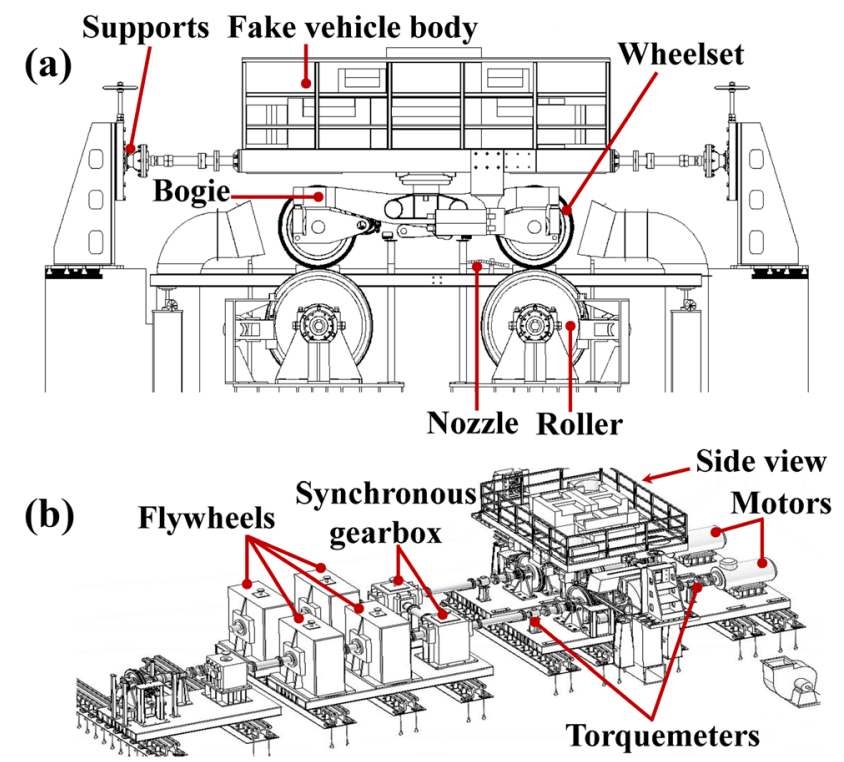

Fig. 3 Schematic of the full-scale wheel-rail roller rig [44]: a side view; b global view

Table 1 Parameters of the full-scale wheel-rail roller rig [44]

\begin{tabular}{ll}
\hline Parameters & Value \\
\hline Speed range & $0-400 \mathrm{~km} / \mathrm{h}$ \\
Axle load & $6-15 \mathrm{t}$ \\
Diameter of wheel & $860 \mathrm{~mm}$ \\
Diameter of roller & $1250 \mathrm{~mm}$ \\
Material of wheel & ER8 \\
Material of wheel & U71Mn \\
Bogie type & SWMB-400 \\
Type of wheel tread & LMA \\
Type of rail head & T60 \\
Water flow & $0.5 \mathrm{~L} / \mathrm{min}$ \\
\hline
\end{tabular}

dependent variable, which is quite different from the description of Coulomb's law. Bochet [9] established the relationship between falling friction and sliding speed by using the test data from Poiree, who conducted experiments (with sliding speed up to $22 \mathrm{~m} / \mathrm{s}$ ) with a wheel sliding over a rail on the Lyon line. The falling friction between the wheel and rail has been verified on various friction testers in recent years. Pei [45] carried out a friction test on a wheel and rail sample on the tribology tester MHK-500. During the test, the rotating test rig, driven by the motor speed, was pressed on the static test block. The tested rotational speed was $100-200 \mathrm{r} / \mathrm{min}$, which was equivalent to a wheel sliding speed of $1-20 \mathrm{~km} / \mathrm{h}$. The normal force was loaded by weights and levers. Weights of $300 \mathrm{~kg}$ and $400 \mathrm{~kg}$ were selected to simulate the heavy loads between 
wheel and rail. The test blocks were brand-new to avoid the influence of surface contamination, and sometimes the test process was stopped considering the effect of frictional heat. The results showed that the friction coefficient decreased with the increase in the sliding speed. After the speed increased to a certain value, the friction coefficient decreased more slowly. Deters and Poksch [46, 47] found that the traction coefficient decreased slightly when the circumferential speeds were increased while keeping the creep and the number of contacts constant by using a test roller. Chen [48] also found that the friction coefficient decreased with increasing speed by using a pendulum rig.

The decrease in the adhesion-creepage curve after saturation is caused by the decreasing friction observed by various experiments. Based on this point, in their subsequent studies, Kalker and Piotrowski [49] used a modified Coulomb model with dual friction coefficients to replace the classical Coulomb model. A static friction coefficient $f_{\text {stat }}$ and a kinetic friction coefficient $f_{\text {kin }}\left(f_{\text {kin }}<f_{\text {stat }}\right)$ were applied to the adhesion and sliding area in the contact area, respectively. This modified Coulomb model with dual friction coefficients was applied successively to the simplified theory FASTSIM algorithm and exact theory CONTACT program. The FASTSIM algorithm and CON$T A C T$ program have been used extensively in the wheelrail contact field, and the latter is currently considered the "gold standard" for wheel-rail contact models. This modified Coulomb model with dual friction coefficients only partially explains the difference between the calculated and measured adhesion coefficients, as shown in Fig. 4. Therefore, more practical friction models need to be developed.

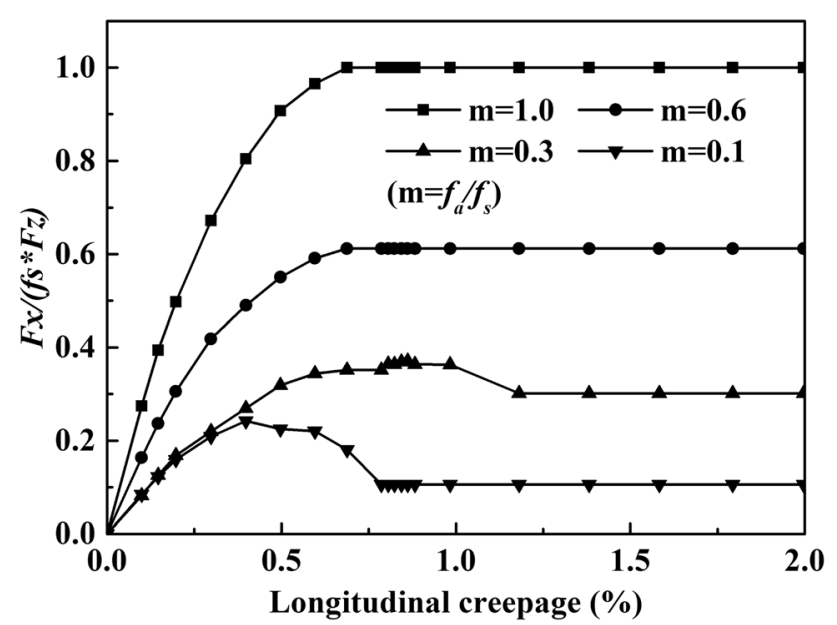

Fig. 4 Calculated adhesion-creepage curves by using a modified Coulomb model (adapted from [45], $f_{a}$ : kinetic friction coefficient, $f_{s}$ : static friction coefficient)

\subsection{The Linear Model + Coulomb Model}

The variation in the friction coefficient with the sliding speed in the linear model can be described by a first-order equation, as expressed in Eq. (3). The negative slope of the function reflects the tendency for the friction coefficient to decrease with the sliding speed.

$f=a-b v$,

where $f$ is the friction coefficient, $a$ and $b$ are the undetermined parameters, and $v$ is the sliding speed.

From Eq. (3), it can be obtained that the friction coefficient decreases continuously with the increase in sliding speed. However, in the actual research, it is found that the drop rate of the friction coefficient gradually flattens with the increase in sliding speed [35, 50-52]. The constant negative slope determines that the linear model cannot accurately describe the variation in the friction coefficient over the entire speed range. Therefore, the linear model is generally used together with the Coulomb model in practical applications. The expression of the linear mode + Coulomb model is shown in Eq. (4). The linear model is adopted in the speed range during which the friction coefficient decreases rapidly, while the Coulomb model is used when the friction coefficient decreases slowly.

$f=a-b v, v \leq v_{c}$,
$f=c, v>v_{c}$

where $f$ is the friction coefficient, $a, b$ and $c$ are the undetermined parameters, $v$ is the sliding speed, and $v_{c}$ is the characteristic speed.

From Eq. (4), it can be found that as $v \rightarrow 0, f \rightarrow$ a, and the parameter $a$ represent the static friction coefficient, as $v \rightarrow \infty, f \rightarrow c$, and the parameter $c$ is related to the asymptote value of the friction coefficient. The main characteristic of this friction model is that it can describe the falling friction approximately to some extent.

Giménez et al. [11] established a linear relationship between the friction coefficient and the local sliding speed, which was integrated into the FASTSIM algorithm. Giménez's model overcomes the limitation caused by the use of a constant friction coefficient in Karkle's simplified theory; its expression is shown in Eq. (5).

$f=f_{s},|v|=0$

$f=f_{s}-\frac{f_{s}-f_{d}}{v_{c}} \cdot|v|, 0 \leq|v| \leq v_{c}$,

$f=f_{d},|v|>v_{c}$

where $f$ is the friction coefficient, $f_{s}$ is the static friction coefficient, $f_{d}$ is the kinetic friction coefficient, $v$ is the sliding speed, and $v_{c}$ is the characteristic speed. 
Compared with Eq. (4), it can be seen that $a=f_{s}, b=$ $\left(f_{s}-f_{d}\right) / v_{c}$ and $c=f_{d}$. As shown in Fig. 5, the friction coefficient takes the maximum value that corresponds to the static friction coefficient $f_{s}$ when the sliding speed is zero. As the sliding speed increases, the friction coefficient decreases in proportion to the speed until the dynamic friction coefficient $f_{d}$ is reached for the characteristic $v_{c}$ value. From this value, the dynamic value of the friction coefficient remains constant.

Giménez's friction model is a typical linear model + Coulomb model, which is commonly used to linearize another complex friction model in order to reduce the calculation work of wheel-rail adhesion [12][52, 53]. However, this model can only describe the constant drop rate of the friction coefficient, which is not flexible enough for defining the friction coefficient. As such, it is seldom seen in practical applications.

\subsection{The Rational Model}

A rational function is suitable for describing a falling phenomenon. Thus, Bochet [9] developed a rational model to describe the wheel-rail friction coefficient. The general expression of the rational model can be seen in Eq. (6). From the equation, it can be found that as $v \rightarrow 0, f \rightarrow(c+b / a)$, which means that $c+b / a$ reflects the static friction coefficient; as $v \rightarrow \infty, f \rightarrow c$, which means that the parameter $c$ is related to the asymptote value of the friction coefficient.

$f=c+\frac{b}{a+v}$,

where $f$ is the friction coefficient, $a, b$ and $c$ are the undetermined parameters, and $v$ is the sliding speed.

The derivative of Eq. (6) with respect to $v$ can be written as follows:

$\frac{\mathrm{d} f}{\mathrm{~d} v}=-\frac{b}{(a+v)^{2}}$.

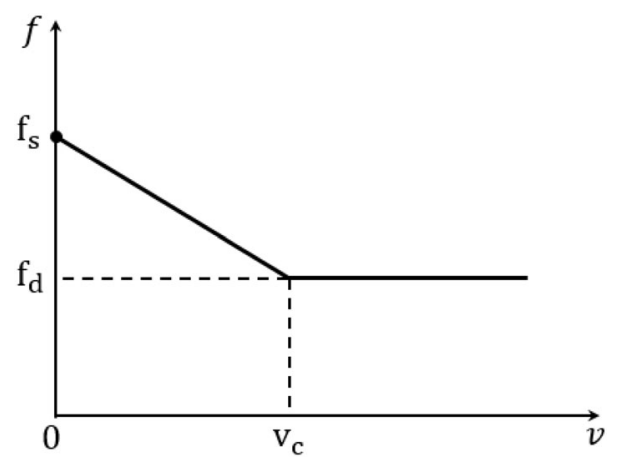

Fig. 5 Giménez's friction model
From Eq. (7), it can be found that the drop rate of the friction coefficient with the speed is nonlinear, which can be adjusted by the two parameters a and b. By setting proper values of $a$ and $b$, the variations in the measured friction curve are well fitted.

The rational model has three control parameters as well, which is the same as the linear model + Coulomb model. But the friction curve controlled by this model is more flexible than the latter, and the fitted curve is more consistent with the fact that the friction coefficient decreases with the increase in the sliding speed.

Bochet [9] used the test data from Poiree, who conducted his experiments (sliding speed of up to $22.0 \mathrm{~m} / \mathrm{s}$ ) with a wheel sliding over a rail on the Lyon line, and obtained an empirical equation as follows:

$f=\frac{f_{s}}{1+0.03 v}$,

where $f$ is the friction coefficient, $v$ is the sliding speed and its unit is $\mathrm{m} / \mathrm{s}$, and $f_{s}$ is the static friction coefficient which is related to the humidity of the rail. For the very dry rail, $f_{s}=0.31$; for the dry rail, $f_{s}=0.22$; and for the moist rail, $f_{s}=0.14$.

The relationship between the friction coefficient and the sliding speed in Bochet's model is shown in Fig. 6. Since Bochet's model is derived from the sliding experiments between the wheel and rail in the field, there is no doubt about its authenticity. Therefore, this rational equation has been used widely for modeling a wheel-rail friction curve [47, 54-56].

The friction curve can be fitted flexibly by using the rational model. However, the falling slope of the actual friction curve is not constant, but varies at different speeds. This means that a local error between the fitted and measured curves is generated in some speed range. One

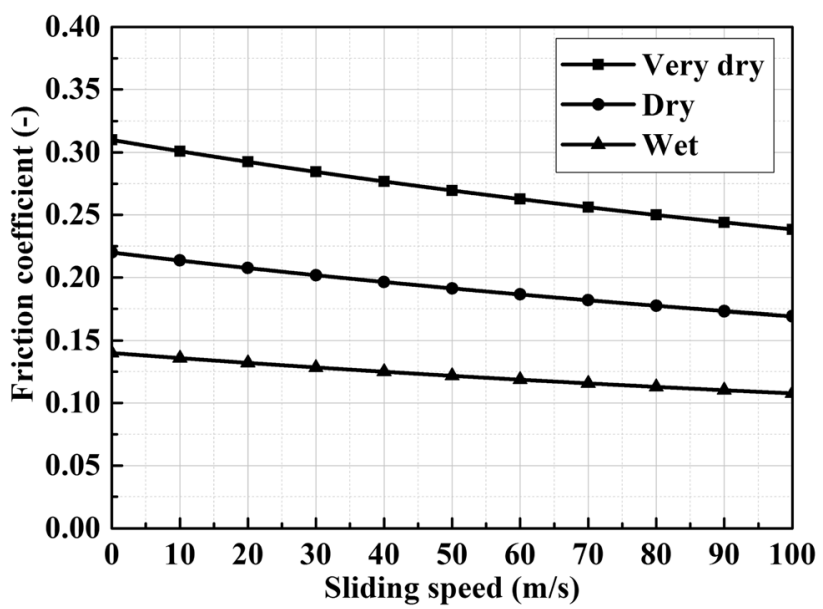

Fig. 6 The relationship between the friction coefficient and the sliding speed in Bochet's model 
possible way to reduce the error was shown in the method used by Zhang et al. [58], and the expression of their model can be seen in Eq. (9). Here, the constant parameters a and b were replaced with variables $f_{s}(v)$ and $\alpha(v)$, respectively, which are related to the speed. The expressions of $f_{s}(v)$ with respect to speed squared and piecewise linear function of $\alpha(v)$ with respect to speed were obtained based on tests. More specific details can be found in Zhang et al. [58]. This approach has greatly enhanced the controllability of the model. By using this improved rational friction model to replace the constant friction coefficient used in FASTSIM, the adhesion coefficients under the water-contaminated condition with various speeds were obtained. The consistency between the numerical results and test results is quite good. The numerical results are highly consistent with the test results.

$f=c+\frac{f_{s}(v)}{1+\alpha(v)}$

Other improved friction models with greater flexibility were developed by Kraft [59] and Fingberg [60] to reduce the error between fitted curves and measurements, as shown in Eq. (10). The improved rational model has five controlling parameters, which relate the friction coefficient to the sliding speed and speed squared. This greatly improves the accuracy of the fitted results, although it also adds significant computational work to wheel-rail adhesion. Xie et al. [53] used this falling friction coefficient in curve simulations for studying curve squeal noise. The friction model described by Eq. (10) was used to replace the original friction coefficient in FASTSIM, and the wheel-rail properties were then obtained. The comparison of creep forces using constant and falling friction coefficients is shown in Fig. 7. After the application by Xie et al., this improved rational model was also used by Croft et al. [61, 62] and Vollebregt et al. [13].

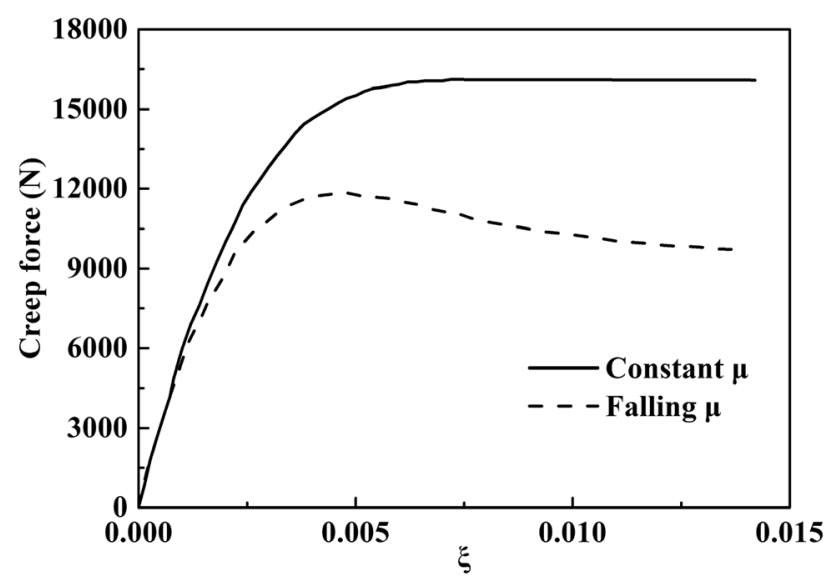

Fig. 7 Comparison of creep forces using constant and falling friction coefficients (adapted from [52], normal force $48000 \mathrm{~N}$ ) $f=c+\frac{b_{1}}{a_{1}+v}+\frac{b_{2}}{a_{2}+v^{2}}$,

where $f$ is the friction coefficient, $a_{1}, a_{2}, b_{1}, b_{2}$ and $c$ are the undetermined parameters, and $v$ is the sliding speed.

Since there are multiple factors affecting the friction coefficient, the undetermined parameters in the model and the friction coefficient obtained are different, even if the same equation is adopted. Table 2 presents a list of the rational models used in the calculation of wheel-rail adhesion. It can be seen that the rational models have widespread application.

\subsection{The Exponential Model}

The general expression of the exponential model is shown in Eq. (11). It can be seen that as $v \rightarrow 0, f \rightarrow(a+c)$, which means that $a+c$ reflects the static friction coefficient; as $v \rightarrow \infty, f \rightarrow c$, which means that the friction coefficient will tend to a stable value $c$ as the speed goes to infinity. The derivative of Eq. (11) with respect to $v$ can be seen in Eq. (12). From Eq. (12), it can be found that the drop rate of the friction coefficient with respect to speed is nonlinear, which can be adjusted by the two parameters $a$ and $b$.

A characteristic of the exponential equation is that if the exponential item is negative, the equation value decreases rapidly at first and then gradually approaches zero with the increase in the independent variable. This characteristic is suitable for describing the falling friction. Therefore, the exponential friction model has been widely used to calculate wheel-rail adhesion [63-72]. A comparison of the adhesion curves between the calculations with the exponential model and measurements with the locomotive is

Table 2 The rational models used for wheel-rail adhesion calculation

\begin{tabular}{lll}
\hline No. & Friction models & References \\
\hline 1 & $f=\frac{f_{s}}{1+0.03 v}{ }^{(1)}$ & Bochet [9] \\
2 & $f=\frac{f_{s}}{1+0.23 v}{ }^{2}$ & Chen [55] \\
3 & $f=\frac{f_{s}(v)}{1+\alpha(v) v}{ }^{3}$ & Zhang et al. [58] \\
4 & $f=0.15+\frac{0.45}{3+v}$ & Vollebregt and Schuttelaars [13] \\
5 & $f=\frac{0.408}{1+0.11 v}$ & Chen [48] \\
6 & $f=\frac{0.03}{0.2+v}+\frac{15}{100+v^{2}}$ & Vollebregt and Schuttelaars [13] \\
& & Xie et al. [53] \\
7 & $f=\frac{0.3}{2+v}+\frac{15}{100+v^{2}}$ & Croft et al. [61, 62] \\
8 & $f=\frac{0.003}{0.02+v}+\frac{15}{100+v^{2}}$ & Croft et al. [62] \\
\hline
\end{tabular}

(1) Very dry, $f_{s}=0.31$; dry, $f_{s}=0.22$; moist, $f_{s}=0.14$; (2) $f_{s}=0.3$; (3) $f_{s}(v)$ and $\alpha(v)$ are the functions of the speed, which are related to the axle load and speed 
shown in Fig. 8. It can be observed that the consistency between the calculations and measurements is quite good.

$f=a e^{-b v}+c$

$\frac{d f}{d v}=-a b e^{-b v}$,

where $f$ is the friction coefficient, $a, b$ and $c$ are the undetermined parameters, and $v$ is the sliding speed.

In 1965, Savkoor [73] established the relationship between the friction coefficient and sliding speed with regard to the rubber tire and road, and its expression can be written as Eq. (13). In his doctoral dissertation [74], Savkoor presented a detailed explanation of this model. Compared with Eq. (11), Savkoor used a logarithm of the speed to replace the speed used in Eq. (11).

$f=f_{0}+\left(f_{m}-f_{0}\right) e^{-h^{2} \log ^{2} \frac{v}{v_{m}}}$,

where $f$ is the friction coefficient, $v$ is the sliding speed, $f_{0}$ and $f_{m}$ are the static friction coefficient and the peak friction coefficient, respectively, $h$ is the undetermined parameter which is related to the given elastic contact body, and $v_{m}$ is the speed corresponding to the peak friction coefficient and it is related to the temperature. This change in the exponential component results in a friction model with four controlling parameters. The combination of the exponential equation and logarithmic equation greatly enhanced the controllability of the friction coefficient. Savkoor's exponential model is not only used for fitting the test results, but it also links its parameters to the physical quantities. In other words, the exponential model developed by Savkoor has physical meaning. After some modifications, Savkoor's model was applied to the calculation of wheel-rail adhesion by Vollebregt [13, 75].

Because they can accurately describe the falling friction coefficient, exponential models are widely applied to wheel-rail adhesion calculations, as seen in Table 3.

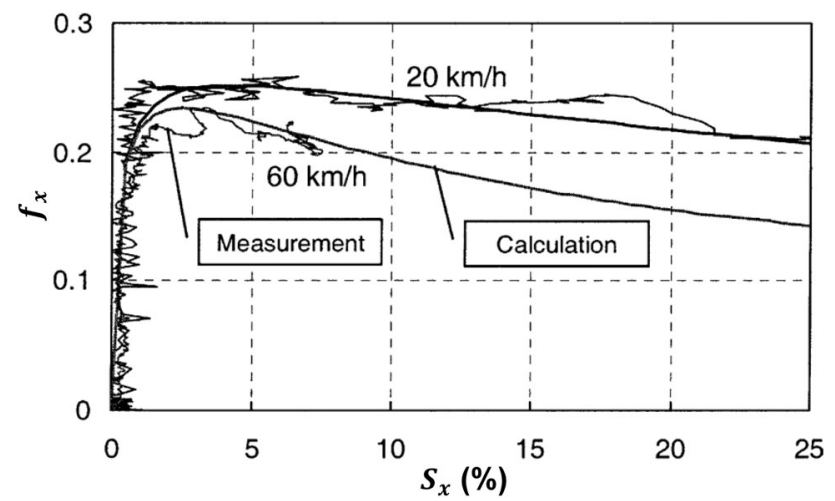

Fig. 8 Adhesion curves based on the measurements with the Bombardier locomotive 12X (adapted from [64])
Table 3 The exponential models used for wheel-rail adhesion calculation

\begin{tabular}{lll}
\hline No. & Friction models & References \\
\hline 1 & $f=\mu_{0}\left(A+(1-A) e^{-B \omega}\right)^{(1)}$ & Polach [63, 64] \\
& & $\begin{array}{l}\text { Spiryagin et al. [65, 66] } \\
\text { Voltr and Lata [67] }\end{array}$ \\
& & Rovir et al. [12] \\
3 & $f=\mu_{0}\left(\alpha+(1-\alpha) e^{-\beta \gamma}\right)^{2}$ & Piotrowski [68] \\
& $f=0.175+0.175 e^{-1.5 v}$ & An et al. [69, 70] \\
& $f=0.32+0.18 e^{-6 v}$ & Zhao and Li [71] \\
& & Yang et al. [72] \\
& & Vollebregt and Schuttelaars [13] \\
5 & $f=0.15+0.15 e^{-\log ^{2 \frac{2}{3}}}$ & Vollebregt [75]
\end{tabular}

(1) $\mu_{0}$ is the static friction coefficient, $\omega$ is the creepage, and $\mu_{0}, A$ and $B$ are the undetermined parameters related to normal force and interface conditions. (2) $\mu_{0}$ is the static friction coefficient, $\gamma$ is the creepage, and $\mu_{0}, \alpha$ and $\beta$ are the undetermined parameters related to normal force and interface conditions

\section{Discussion}

To compare the effects of different friction models, four types of friction models (Coulomb model, linear model + Coulomb model, rational model and exponential model) were adopted to calculate the adhesion coefficients. The calculated adhesion-creepage curves were compared with the measured curves. The latter were tested by the authors on a full-scale roller rig under wet conditions. The simulated axle load was $13 \mathrm{t}$, and the maximum test speed was $200 \mathrm{~km} / \mathrm{h}$. Polach's model [63, 64] is a simplified version of FASTSIM, which is itself a simplified model of Kalker's 3D exact theory. Though the accuracy of the former is lower because of simplification, it is much faster than the latter two [14]. Considering that it allows us to simulate various real wheel-rail contact conditions, especially water contamination, Polach's model was adopted to calculate the adhesion-creepage curves. The expression of Polach's model is shown in Eq. (14). The original friction model used in Polach's model can be seen in Table 2. Here the original friction model was replaced by the models listed in Eqs. (16) and (17), respectively.

$\mu=\frac{2 f}{\pi}\left(\frac{\varepsilon}{1+\varepsilon^{2}}+\arctan \varepsilon\right)$

with

$\varepsilon=\frac{2}{3} \frac{C \pi a^{2} b}{Q f} s$,

where $\mu$ is the adhesion coefficient, $f$ is the friction coefficient, $\varepsilon$ is the gradient of the tangential stress in the area 
of adhesion, $a$ and $b$ are the half-axles of the contact ellipse, $Q$ is the wheel load, and $s$ is the total creep.

The unknown parameters of the friction models can be determined by the static friction coefficient, asymptotic value and one point on the adhesion-creep curve, as seen in Eqs. (16) and (17). Substituting Eqs. (16) and (17) into Eq. (14), the corresponding adhesion coefficients are obtained, which are plotted in Fig. 9.

For $v=190 \mathrm{~km} / \mathrm{h}$,

$f_{C}=0.19$

$f_{L}=\max (0.19-0.005 v, 0.16)$

$f_{-R}=\frac{0.19}{1+0.03 v}$

$f_{-E}=0.1+0.09 e^{-0.06 v}$

For $v=200 \mathrm{~km} / \mathrm{h}$,

$f_{C}=0.2$

$f_{-L}=\max (0.2-0.02 v, 0.1)$

$f_{-R}=\frac{0.2}{1+0.1 v}$

$f_{-E}=0.1+0.1 e^{-0.25 v}$

where $f_{-} C, f_{-} L, f_{-} R$ and $f_{-}$are the friction coefficient of the Coulomb model, linear model + Coulomb model, rational model and exponential model, respectively, $v$ is the sliding speed and its unit is $\mathrm{m} / \mathrm{s}$.

The adhesion coefficient calculated using the Coulomb model remains constant after reaching its saturation value. This result is consistent with the conclusions obtained by previous studies, such as Carter [5] and Kalker [17]. The adhesion-creepage curve calculated by the linear model + Coulomb model falls linearly after reaching its peak value, until the creepage reaches the characteristic value. From this value, the adhesion coefficient remains constant. The adhesion-creepage curves calculated by the rational model and the exponential model have the best agreement with the measured adhesion curves. The adhesion-creepage curve of the rational model is slightly higher than that of the exponential model before the creepage reaches a certain value. In this case study, the characteristic creepage is about $12 \%$. Over the creepage, the adhesion curve of the exponential model is higher than that of the rational model. In addition, the falling slope of the adhesion curves of the exponential model decreases with the increase in the creepage, and finally tends to zero. It can be inferred that the gap between the adhesion coefficients of the rational model and the exponential model continues to increase.

Comparing these four friction models, it can be seen that the rational model and the exponential model are superior for fitting the measured adhesion curves. There is little difference between their calculated adhesion coefficients in a certain creepage range. At the large creepage stage, the adhesion-creepage curve obtained by the exponential model falls more gradually, while that by the rational model has a relatively sharp decline. These two models can be chosen for application according to the variation in the actual adhesion curve.

However, an interesting phenomenon was observed in the tests, in that the adhesion-creepage curves do not always decrease monotonically after saturation, and sometimes have a secondary peak or increase continually after reaching the valley, as seen in Fig. 10. More details about the results can be seen in Zhou et al. [44]. Similar experimental phenomena are found in the work of Boiteux [76], Zhang et al. [58], Voltr et al. [67] and Bosso et al. $[77,78]$. This phenomenon of increasing adhesion after saturation is indicated as adhesion recovery. The thermal effect due to the wheel-rail frictional heat and cleaning effect are considered the main reasons for the adhesion recovery $[67,77,78]$. Up to now, there has been no definite theory regarding adhesion recovery. The existing falling friction model is unable to describe these novel adhesion phenomena. Developing a novel and practical friction
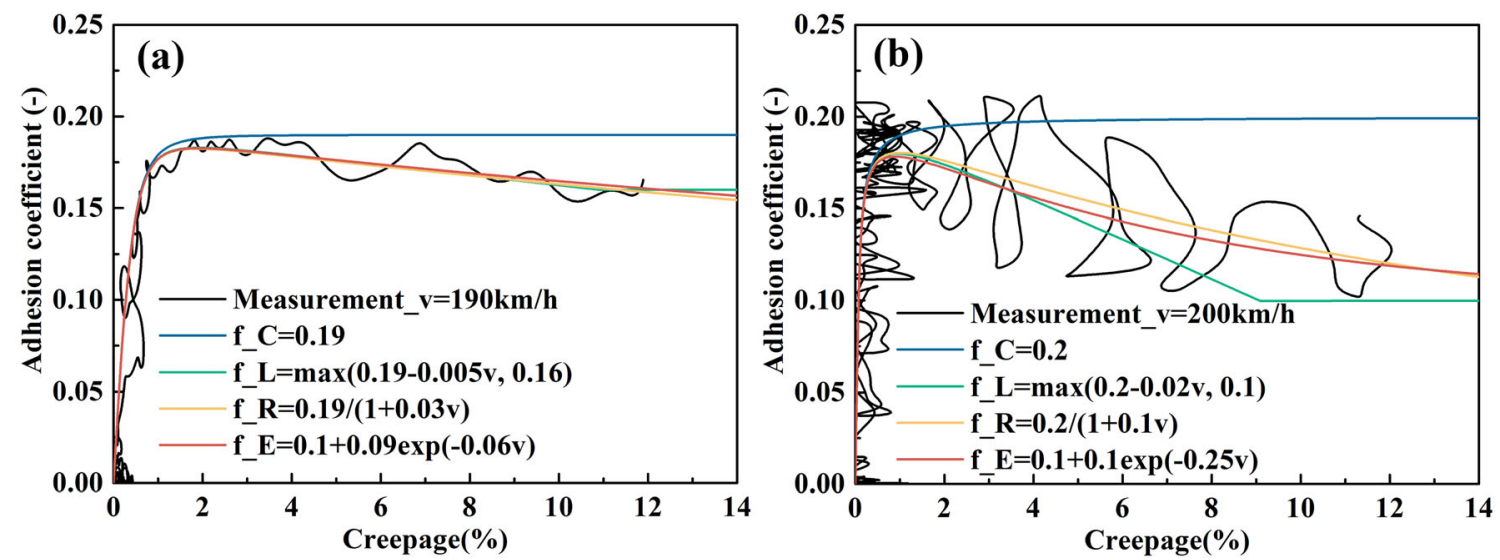

Fig. 9 Calculated and measured adhesion-creepage curves. a $190 \mathrm{~km} / \mathrm{h}$; b $200 \mathrm{~km} / \mathrm{h}$ 

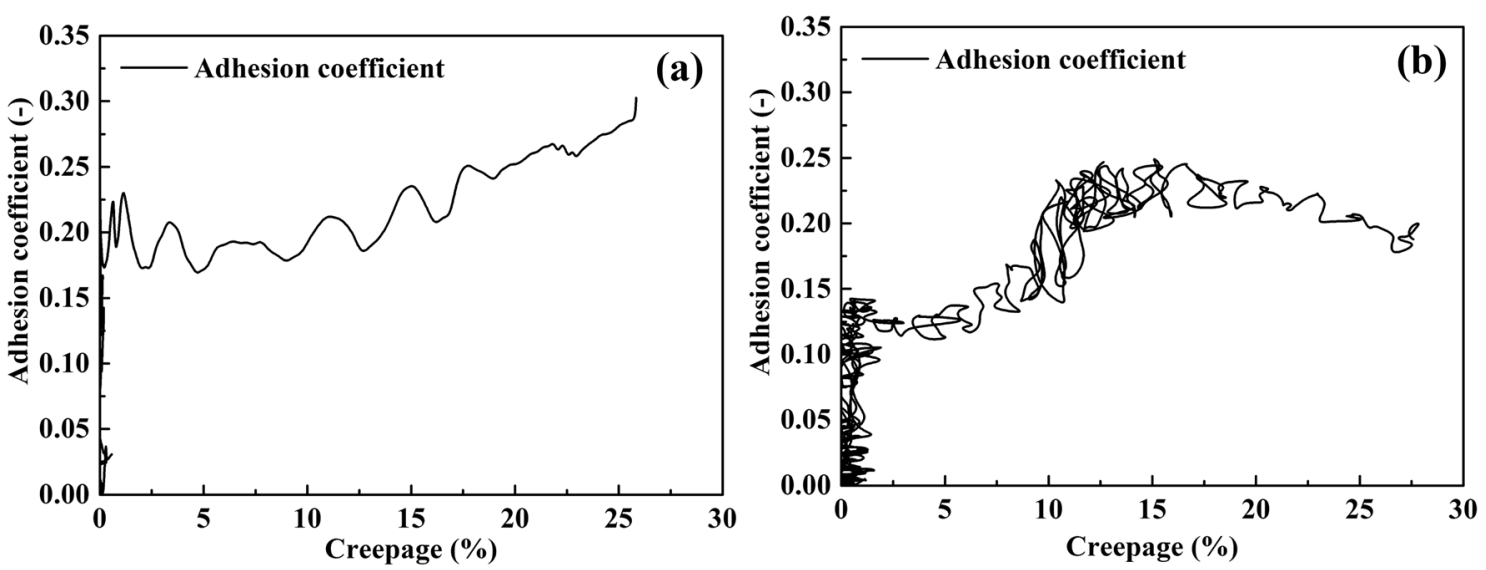

Fig. 10 Adhesion recovery. a $120 \mathrm{~km} / \mathrm{h}$, axle load $7 \mathrm{t}$; b $150 \mathrm{~km} / \mathrm{h}$, axle load 7 t

model to accurately describe the wheel-rail friction behavior is still an essential but challenging and significant task.

\section{Conclusion}

The critical role of friction in the calculation of wheel-rail adhesion was discussed. Four types of friction models (Coulomb model, linear model + Coulomb model, rational model and exponential model) which are commonly used for the calculation of wheel-rail adhesion were reviewed, in particular with regard to their structural characteristics and application state. The adhesion coefficients calculated from these four friction models using Polach's model were analyzed by comparison with the measured values.

- The rational model and the exponential model are more flexible for defining the falling friction, and the adhesion coefficients calculated by these two models are highly consistent with the measured values.

- The existing falling friction model is unable to describe the adhesion recovery phenomenon. Developing a novel and practical friction model to accurately describe wheel-rail friction behavior is still an essential but challenging and significant task.

Open Access This article is licensed under a Creative Commons Attribution 4.0 International License, which permits use, sharing, adaptation, distribution and reproduction in any medium or format, as long as you give appropriate credit to the original author(s) and the source, provide a link to the Creative Commons licence, and indicate if changes were made. The images or other third party material in this article are included in the article's Creative Commons licence, unless indicated otherwise in a credit line to the material. If material is not included in the article's Creative Commons licence and your intended use is not permitted by statutory regulation or exceeds the permitted use, you will need to obtain permission directly from the copyright holder. To view a copy of this licence, visit http://creativecommons. org/licenses/by/4.0/.

\section{References}

1. Simon I (2006) Handbook of railway vehicle dynamic. CRC Press/Taylor and Francis

2. Bosso N, Spiryagin M, Gugliotta A, Soma A (2013) Mechatronic modeling of real-time wheel-rail contact. Springer, Berlin

3. Haines DJ, Ollerton E (1963) Contact stress distributions on elliptical contact surfaces subjected to radial and tangential forces. Proc Inst Mech Eng 177(1):95-114

4. Garg VK, Dukkipati RV (1984) Dynamics of railway vehicle systems. Academic Press

5. Carter FW (1926) On the action of a locomotive driving wheel. Proc R Soc A- Math, Phys Eng Sci 112(760):151-157

6. Fromm H (1927) Berechnung des Schlupfes beim Rollen deformierbarer Scheiben (Calculation of the slipping in the case of rolling deformable bars). Zeitschrift für angewandte Mathematik und Mechanik (J Appl Math Mech) 7(1):27-58

7. Amontons G (1699) De la résistance causée dans les machines The resistance caused in the machines. Mémoires de l'Academie des Royale: 203-222

8. Coulomb CA (1785) Théorie des machines simples (Simple mechanical theory). Mémoires de Mathématique et de Physique de l'Academie des Sciences: 161-331

9. Bochet H (1858) Du frottement de glissement spécialement sur les rails des chemins de fer (Sliding friction especially on railroad tracks). Dalmont et Dunod, Paris

10. Kragelski IV, Dobyčin MN, Kombalov VS (1982) Friction and wear-calculation methods. Pergamon Press, Oxford

11. Giménez JG, Alonso A, Gómez E (2005) Introduction of a friction coefficient dependent on the slip in the FastSim algorithm. Veh Syst Dyn 43(4):233-244

12. Rovira A, Roda A, Lewis R, Marshall MB (2012) Application of Fastsim with variable coefficient of friction using twin disc experimental measurements. Wear 274:109-126

13. Vollebregt EAH, Schuttelaars HM (2012) Quasi-static analysis of two-dimensional rolling contact with slip-velocity dependent friction. J Sound Vib 331(9):2141-2155

14. Meymand SZ, Keylin A, Ahmadian MA (2016) Survey of wheelrail contact models for rail vehicles. Veh Syst Dyn 54(3):386-428

15. Poritsky H (1950) Stresses and deflections of cylindrical bodies in contact with application to contact of gears and of locomotive wheels. J Appl Mech-Trans ASME 17:191-201

16. Knothe K, Stichel S (2017) Rail vehicle dynamics. Springer, New York

17. Kalker JJ (1966) Rolling with slip and spin in the presence of dry friction. Wear 9(1):20-38 
18. Kalker JJ (1967) On the rolling contact of two elastic bodies in the presence of dry friction Doctoral dissertation. Delft University of Technology, Delft

19. Kalker JJ (1971) A minimum principle for the law of dry friction, with application to elastic cylinders in rolling contact. Part 1: Fundamentals-Application to steady rolling. J Appl Mech-Trans ASME 875-880

20. Kalker JJ (1977) Variational principles of contact elastostatics. IMA J Appl Math 20(2):199-219

21. Kalker JJ (1979) The computation of three-dimensional rolling contact with dry friction. Int J Numer Meth Eng 14(9):1293-1307

22. Bentall RH, Johnson KL (1967) Slip in the rolling contact of two dissimilar elastic rollers. Int J Mech Sci 9(6):389-404

23. Vermeulen PJ, Johnson KL (1964) Contact of nonspherical elastic bodies transmitting tangential forces. J Appl Mech-Trans ASME 31(2):338

24. Shen ZY, Hedrick JK, Elkins JA (1983) A comparison of alternative creep force models for rail vehicle dynamic analysis. Veh Syst Dyn 12(1-3):79-83

25. Kalker JJ (1982) A fast algorithm for the simplified theory of rolling contact. Veh Syst Dyn 11(1):1-13

26. Arslan MA, Kayabaşı O (2012) 3-D rail-wheel contact analysis using FEA. Adv Eng Softw 45(1):325-331

27. Vo KD, Tieu AK, Zhu HT, Kosasih PB (2014) A 3D dynamic model to investigate wheel-rail contact under high and low adhesion. Int J Mech Sci 85:63-75

28. Zhao X, Wen ZF, Zhu MH, Jin XS (2014) A study on high-speed rolling contact between a wheel and a contaminated rail. Veh Syst Dyn 52(10):1270-1287

29. Yang Z, Li ZL, Dollevoet R (2016) Modelling of non-steady-state transition from single-point to two-point rolling contact. Tribol Int 101:152-163

30. Toumi M, Chollet H, Yin H (2016) Finite element analysis of the frictional wheel-rail rolling contact using explicit and implicit methods. Wear 366-367:157-166

31. Li ZL, Zhao X, Dollevoet R (2017) An approach to determine a critical size for rolling contact fatigue initiating from rail surface defects. Int J Rail Transp 5(1):16-37

32. Naeimi M, Li SG, Li ZL, Wu J, Petrov RH, Sietsma J, Dollevoet R (2018) Thermomechanical analysis of the wheel-rail contact using a coupled modelling procedure. Tribol Int 117:250-260

33. Lian QL, Deng GY, Tieu AK, Li HJ, Liu ZM, Wang X (2020) Thermo-mechanical coupled finite element analysis of rolling contact fatigue and wear properties of a rail steel under different slip ratios. Tribol Int 141:105943

34. Koffman J (1948) Adhesion and friction in rail traction. J Inst Loco Eng 38(205):593-672

35. Broster M, Pritchard C, Smith DA (1974) Wheel/rail adhesion: its relation to rail contamination on British railways. Wear 29(3):309-321

36. John RD (1978) A study of rolling adhesion in braking. Master thesis, Virginia Polytechnic Institute and State University, Virginia

37. Logston CF, Itami GS (1980) Locomotive friction-creep studies. J Manuf Sci Eng-Trans ASME 102(3):275-281

38. Alzoubi MF (1998) Adhesion-creepage characteristics of wheel/ rail system under dry and contaminated rail surfaces Doctoral dissertation. Illinois Institute of Technology, Illinois

39. Baek K, Kyogoku K, Nakahara T (2007) An experimental investigation of transient traction characteristics in rolling-sliding wheel/rail contacts under dry-wet conditions. Wear 263(1-6):169-179

40. Baek K, Kyogoku K, Nakahara T (2008) An experimental study of transient traction characteristics between rail and wheel under low slip and low speed conditions. Wear 265(9-10):1417-1424
41. Malvezzi M, Allotta B, Pugi L (2008) Feasibility of degraded adhesion tests in a locomotive roller rig. Proc Inst Mech Eng Part F-J Rail and Rapid Transit 222(1):27-43

42. Yi Z (2011) Adhesion in the wheel-rail contact under contaminated conditions Doctoral dissertation. KTH Royal Institute of Technology, Stockholm

43. Ridofi A, Allotta B, Conti R, Meli E (2015) Modeling and control of a full-scale roller-rig for the analysis of railway braking under degraded adhesion conditions. IEEE Trans Contr Syst $\mathrm{T}$ 23(1):186-196

44. Zhou JJ, Wu ML, Tian C, Yuan ZW, Chen C (2020) Experimental investigation on wheel-rail adhesion characteristics under water and large sliding conditions. Ind Lubr Tribol: https://doi. org/10.1108/ILT-07-2020-0236

45. Pei YF (1996) Research on the mechanism of wheel-rail adhesion in high-speed railway Doctoral dissertation. Tsinghua University, Beijing

46. Deters L, Poksch M (2003) Friction behaviour and wear properties of rail and wheel material. Materialwiss Werkstofftech 34(1011):953-959

47. Deters L, Proksch M (2005) Friction and wear testing of rail and wheel material. Wear 258(7):981-991

48. Chen K (2017) Experimental study on influencing factors of friction coefficient of wheel. Master thesis, Lanzhou Jiaotong University, Lanzhou

49. Kalker JJ, Piotrowski J (1989) Some new results in rolling contact. Veh Syst Dyn 18(4):223-242

50. Beagley TM (1975) Laboratory investigation into wheel/rail adhesion doctoral dissertation. University of Leicester, Leicester

51. Chang CY, Chen B, Cai YW, Wang JB (2019) An experimental study of high speed wheel-rail adhesion characteristics in wet condition on full scale roller rig. Wear 440:203092

52. Chang CY, Chen B, Cai YW, Wang JB (2019) Experimental study on adhesion property of high speed wheel and rail in wet condition by full scale roller rig. China Railway Sci 40(2):25-32

53. Xie G, Allen PD, Iwnicki SD, Alonso A, Thompson DJ, Jones CJC, Huang ZY (2006) Introduction of falling friction coefficients into curving calculations for studying curve squeal noise. Veh Syst Dyn 44(s1):261-271

54. Alonso A, Giménez JG (2008) Non-steady state contact with falling friction coefficient. Veh Syst Dyn 46(s1):779-789

55. Chen HC (1997) On the rolling contact of high speed wheel/rail system Doctoral dissertation. Academy of Railway Sciences of China, Beijing

56. Xiao Q, Lin FT, Wang CG, Che XY (2012) Analysis on wheelrail contact characteristics with variable friction coefficient. J China Railway Soc 34(6):24-28

57. Xu HX (2014) The analysis on the creep behavior of high-speed wheel/rail in different condition. Master thesis, East China Jiaotong University, Nanchang

58. Zhang WH, Chen JZ, Wu XJ, Jin XS (2002) Wheel/rail adhesion and analysis by using full scale roller rig. Wear 253(1):82-88

59. Kraft K (1967) Der enfluss der fahrgeschwindigkeit auf den haftwert zwischen rad und schiene. Archiv fur Eisenbahntechnik 22:58-78

60. Fingberg U (1982) Ein model fur das kurvenquietschen von schiennenfahrzeugen. Fortschritt-Berichte VDI 11:140

61. Croft B, Jones C, Thompson D (2011) Velocity-dependent friction in a model of wheel-rail rolling contact and wear. Veh Syst Dyn 49(11):1791-1802

62. Croft BE, Vollebregt EAH, Thompson DJ (2012) An investigation of velocity-dependent friction in wheel-rail rolling contact. In: Noise and vibration mitigation for rail transportation systems, Notes on numerical fluid mechanics and multidisciplinary design, Tokyo 
63. Polach O (2001) Rad-schiene-modelle in der simulation der fahrzeug-und antriebsdynamik (Wheel-rail models in the simulation of vehicle and drive dynamics). Elektrische Bahnen 99(5):219-230

64. Polach O (2005) Creep forces in simulations of traction vehicles running on adhesion limit. Wear 258(7-8):992-1000

65. Spiryagin M, Polach O, Cole C (2013) Creep force modelling for rail traction vehicles based on the Fastsim algorithm. Veh Syst Dyn 51(11): 1765-1783

66. Spiryagin M, Wu Q, Duan K, Cole C, Sun YQ, Person I (2016) Implementation of a wheel-rail temperature model for locomotive traction studies. Int J Rail Transp 5(1):1-15

67. Voltr P, Lata M (2015) Transient wheel-rail adhesion characteristics under the cleaning effect of sliding. Veh Syst Dyn 53(5):605-618

68. Piotrowski J (2010) Kalker's algorithm Fastsim solves tangential contact problems with slip-dependent friction and friction anisotropy. Veh Syst Dyn 48(7):869-889

69. An BY (2015) An analysis of the transient high-speed wheel-rail rolling contact in the presence of a wheel flat. Master thesis, Southwest Jiaotong University, Chengdu

70. An BY, Ma DL, Wang P, Xu JM, Du YL (2017) Study on influence of slip-dependent friction on wheel/rail rolling contact. J China Railway Soc 39(07):98-104
71. Zhao X, Li ZL (2016) A solution of transient rolling contact with velocity dependent friction by the explicit finite element method. Eng Comput 33(4):1033-1050

72. Yang Z, Deng X, Li ZL (2019) Numerical modeling of dynamic frictional rolling contact with an explicit finite element method. Tribol Int 129:214-231

73. Savkoor AR (1966) Some aspects of friction and wear of types arising from deformations, slip and stresses at the ground contact. Wear 9(1):66-78

74. Savkoor AR (1987) Dry adhesive friction of elastomers: a study of the fundamental mechanical aspects Doctoral dissertation. Delft University of Technology, Delft

75. Vollebregt EAH (2015) FASTSIM with falling friction and friction memory. In: Noise and vibration mitigation for rail transportation systems, Notes on numerical fluid mechanics and multidisciplinary design, Berlin

76. Boiteux M (1986) Le problèmes de I'adhérence en freinage. RGCF fév 105:59-71

77. Bosso N, Magelli M, Zampieri, N (2019) Investigation of adhesion recovery phenomenon using a scaled roller-rig. Veh Syst Dyn: $1-18$

78. Bosso N, Gugliotta A, Magelli M, Zampieri N (2019) Experimental setup of an innovative multi-axle roller rig for the investigation of the adhesion recovery phenomenon. Exp Tech 43(2):695-706 